\title{
A IMPORTÂNCIA DO CONTROLE DE FLUXO DE CAIXA PARA AS MICRO E PEQUENAS EMPRESAS
}

Angélica Pereira Ferreira, Eduardo Teraoka Tófoli, Irene Caires da Silva.

Universidade do Oeste Paulista - UNOESTE, Especialização em MBA Finanças e Controladoria, Presidente Prudente, SP. E-mail: angelica.pereira25@hotmail.com, eduardotofoli@yahoo.com.br, irene@unoeste.br.

\section{RESUMO}

Com a globalização, as empresas passam por mudanças constantes. A concorrência, cada dia mais acirrada e a economia exigindo maior eficiência das empresas. Com isso, as mesmas precisam ser mais dinâmicas e controladas, e encontramos no controle de fluxo de caixa uma ferramenta excelente para sua sobrevivência. Desta forma, o presente artigo provém de uma pesquisa bibliográfica e o seu estudo justifica - se pelo fato dos gestores deixarem de realizar um controle financeiro das micro e pequenas empresas pelo motivo destas estarem desobrigadas a elaboração da demonstração do fluxo de caixa. Assim, o objetivo da pesquisa é de verificar a importância do controle de fluxo de caixa para as micros e pequenas empresas. Contudo, percebe-se que, a empresa que se utiliza deste controle consegue ter uma visão melhor da movimentação de seu caixa e obtém informações relevantes que auxiliam no processo de gestão.

Palavras-chave: Fluxo de caixa. Micro e pequenas empresas.Gestão. Informações. Resultados.

\section{THE IMPORTANCE OF CASH FLOW CONTROL FOR MICRO AND SMALL ENTERPRISES}

\begin{abstract}
With globalization, companies undergo constant change. The competition, every day more fierce and the economy demanding greater efficiency of the companies. With this, they need to be more dynamic and controlled, and find in cash flow control an excellent tool for their survival. In this way, the present article comes from a bibliographical research and its study is justified by the fact that the managers no longer carry out a financial control of the micro and small companies because they are not responsible for the elaboration of the cash flow statement. Thus, the goal of the research is to verify the importance of cash flow control for micro and small companies. However, it can be seen that the company that uses this control gets a better view of the movement of its cash and obtains relevant information that helps in the management process.
\end{abstract}

Keywords: Cash flow. Micro and small businesses. Management. Information. Results. 


\section{INTRODUÇÃO}

Em meios à competitividade existente no mundo, os empresários precisam aderir a métodos de gestão que sejam sólidos, completos e eficientes, de modo que façam com que seu empreendimento alavanque no mercado e gere recursos financeiros que sejam suficientes para administrar o seu negócio.

Á vista disto, tem-se a gestão financeira como fator primordial para toda e qualquer empresa, onde traz o controle de fluxo de caixa como um instrumento de suma importância, pois envolve a gestão de toda entrada e saída de recursos monetários.

A importância de se trabalhar a gestão financeira está relacionada ao sucesso que a empresa almeja, por meio dele, consegue-se traçar metas a longo e curto prazo para que os objetivos sejam alcançados, pois o planejamento financeiro é a fonte da continuidade da organização, e sem ele é difícil tomar decisões corretas.

As informações fornecidas por ele são essenciais para empresas de grande, médio e pequeno porte, pois todas devem se preocupar em manter controle das finanças e utilizar o planejamento financeiro como uma das principais ferramentas para o êxito da organização, onde sem um bom planejamento financeiro as chances de a empresa apresentar sucesso ou ser competitiva diminuem, pois ao não conhecer bem suas finanças não saberá utilizá-las de maneira estratégica.

À vista disto, a justificativa de estudar o tema abordado é pelo fato dos gestores das micro e pequenas empresas deixarem de realizar um controle dos recursos financeiros por estas estarem desobrigadas a elaboração da demonstração de fluxo de caixa, prejudicando assim o seu processo de gestão.

Assim, o estudo deste artigo tem como objetivo verificar a importância do controle de fluxo de caixa para as micros e pequenas empresas.

\section{METODOLOGIA}

Segundo Andrade (2010) pesquisa científica é um composto de procedimentos organizados, baseados no raciocínio lógico, que tem como escopo encontrar soluções para problemas utilizando-se de métodos científicos.

Gil (2002) afirma que a pesquisa tem como fundamento as atividades racionais e sistemáticas, que tem como finalidade resultar em respostas para problemas propostos, utilizando-se de métodos, procedimentos científicos e técnicas até se obter um resultado satisfatório.

Para atingir o objetivo desse trabalho foi realizada uma pesquisa bibliográfica, onde utilizou-se de sites oficiais, livros e artigos científicos de vários autores e pesquisadores da área.

Gil (2017, p.28), diz que "a pesquisa bibliográfica é elaborada com base em material já publicado. Tradicionalmente, esta modalidade de pesquisa inclui material impresso, como livros, revistas, jornais, teses, dissertações e anais de eventos científicos".

Já Marconi e Lakatos (apud MANZO, 2017, p. 199) relatam que, "a bibliografia pertinente oferece meios para definir, resolver, não somente problemas já conhecidos, como também explorar novas áreas em que os problemas não se cristalizaram suficientemente".

Para tanto, entende-se que a pesquisa bibliográfica provém do estudo de materiais que foram publicados anteriormente, onde servem de auxílio para os pesquisadores no desenvolvimento do artigo e no alcance do objetivo. 


\section{FUNDAMENTAÇÃO TEÓRICA}

De acordo com a lei complementar 123 de 2006, as Microempresas (ME) são aquelas empresas que possuem um faturamento anual de até $\mathrm{R} \$ 360.000,00$ (trezentos e sessenta mil reais) e as Empresas de Pequeno Porte (EPP), são aquelas que possuem anualmente uma receita bruta superior a $\mathrm{R} \$ 360.000,00$ e inferior a $\mathrm{R} \$ 4.800 .000,00$ (quatro milhões e oitocentos mil reais).

No entanto, a lei 11.638 de 2007 institui a obrigatoriedade da elaboração das demonstrações financeiras apenas para as sociedades anônimas de capital aberto e para as sociedades de capital fechado com patrimônio líquido superior a $\mathrm{R} \$ \mathbf{2 . 0 0 0 . 0 0 0 , 0 0}$ (dois milhões de reais).

Assim, as empresas enquadradas como ME (Microempresa) ou EPP (Empresa de Pequeno Porte), ficam desobrigadas a elaboração desses demonstrativos e, dentre eles, está a demonstração de fluxo de caixa, no qual é tido como um instrumento fundamental para a gestão empresarial.

\section{FLUXO DE CAIXA}

O fluxo de caixa é um "instrumento que permite ao administrador financeiro planejar, organizar, coordenar, dirigir e controlar os recursos financeiros de sua empresa para determinado período" (ZDANOWICZ, 2000, p.19).

Silva (2016, p.37), alega que o "fluxo de caixa é uma ferramenta que controla a movimentação financeira (as entradas e saídas de recursos financeiros) de uma empresa, em um período determinado".

O fluxo de caixa permite uma análise sobre a tomada de decisão em cima da folga de recursos ou necessidade de investimentos, pois demonstra a situação em que a empresa se encontra momentaneamente.

Sá (2008, p.11), define o fluxo de caixa como sendo "o método de captura e registro dos fatos e valores que provoquem alterações no saldo de caixa e sua apresentação em relatórios estruturados, de forma a permitir sua compreensão e análise".

Por sua vez, Gitman (2002, p. 586), afirma que o fluxo de caixa é: [...] "a espinha dorsal da empresa. Sem ele não se saberá quando haverá recursos suficientes para sustentar as operações ou quando haverá necessidade de financiamentos bancários". Empresas que necessitem continuamente de empréstimos de última hora poderão se deparar com dificuldades de encontrar bancos que as financiem.

O fluxo de caixa deve ser controlado pelo gestor, a fim de que evite os problemas com liquidez, pois é o levantamento de entradas e saídas de recursos da empresa.

Contudo, entende-se que o fluxo de caixa é uma ferramenta financeira que controla toda movimentação monetária ocorrida nas contas de disponibilidades da empresa, como caixa, banco e aplicação financeira, durante um determinado período de tempo (SILVA, 2016).

\section{MÉTODO DE ELABORAÇÃO DO FLUXO DE CAIXA}

A elaboração do controle de fluxo de caixa se inicia com a apresentação do saldo inicial da conta caixa, banco e aplicações financeiras e procede com o registro de todas as entradas e saídas monetárias (CHING; MARQUES; PRADO, 2010).

As entradas serão obtidas através da venda de mercadorias ou prestação de serviços, de recebimentos de vendas a prazo, da venda de ativo imobilizado ou até mesmo do lucro gerado pela empresa. Já as saídas ocorrerão devido ao pagamento das obrigações da 
empresa, como despesas, fornecedores, aquisição de novos ativos, pagamento de empréstimos bancários, impostos, dentre outros, como visto na figura abaixo (CHING; MARQUES; PRADO, 2010).

Figura 1. Diagrama do fluxo de caixa

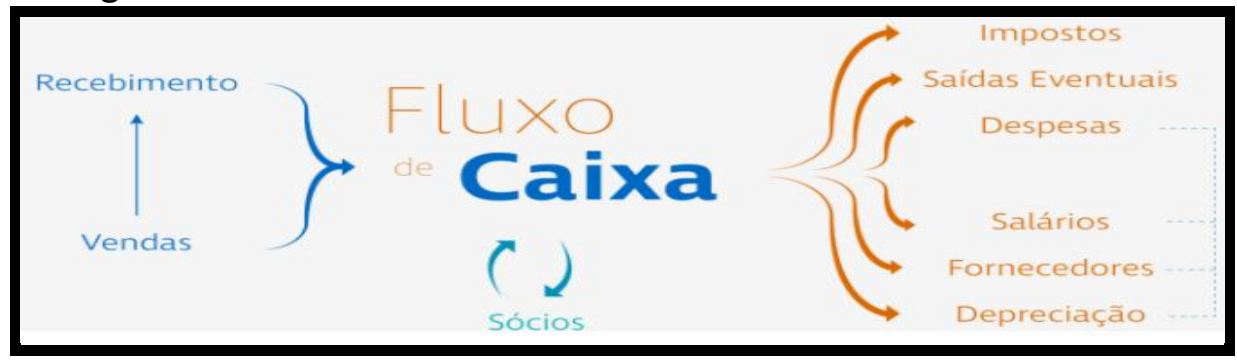

Fonte: Sebrae, (2018)

Acrescenta-se também que é relevante realizar um controle de fluxo de caixa planejado, para antever o valor do capital de giro da empresa em um determinado período.

Tófoli, (2012, p.81) salienta que:

Com o fluxo de caixa feito antecipadamente, o gestor poderá antever situações de falta ou excesso de dinheiro no caixa, quantos e quais serão os compromissos para o período, assim como, a previsão de ingressos de numerários provenientes de venda à vista e de recebimentos de clientes que compraram a prazo.

Com base no argumento trazido pelo autor nota-se que, é preciso controlar e registrar minuciosamente todos os ingressos e desembolsos monetários ocorridos na empresa, e que, através do controle de fluxo de caixa planejado é possível o gestor verificar se a empresa irá dispor de recursos para lidar com as obrigações no dia de seu vencimento.

No entanto, para tal finalidade, o administrador dispõe de diversos métodos que podem ser utilizados para realização deste controle, como obter um sistema informatizado, realizá-lo em um papel ou até mesmo em uma planilha do Excel (TÓFOLI, 2012). 
Figura 2. Planilha para controle de fluxo de caixa

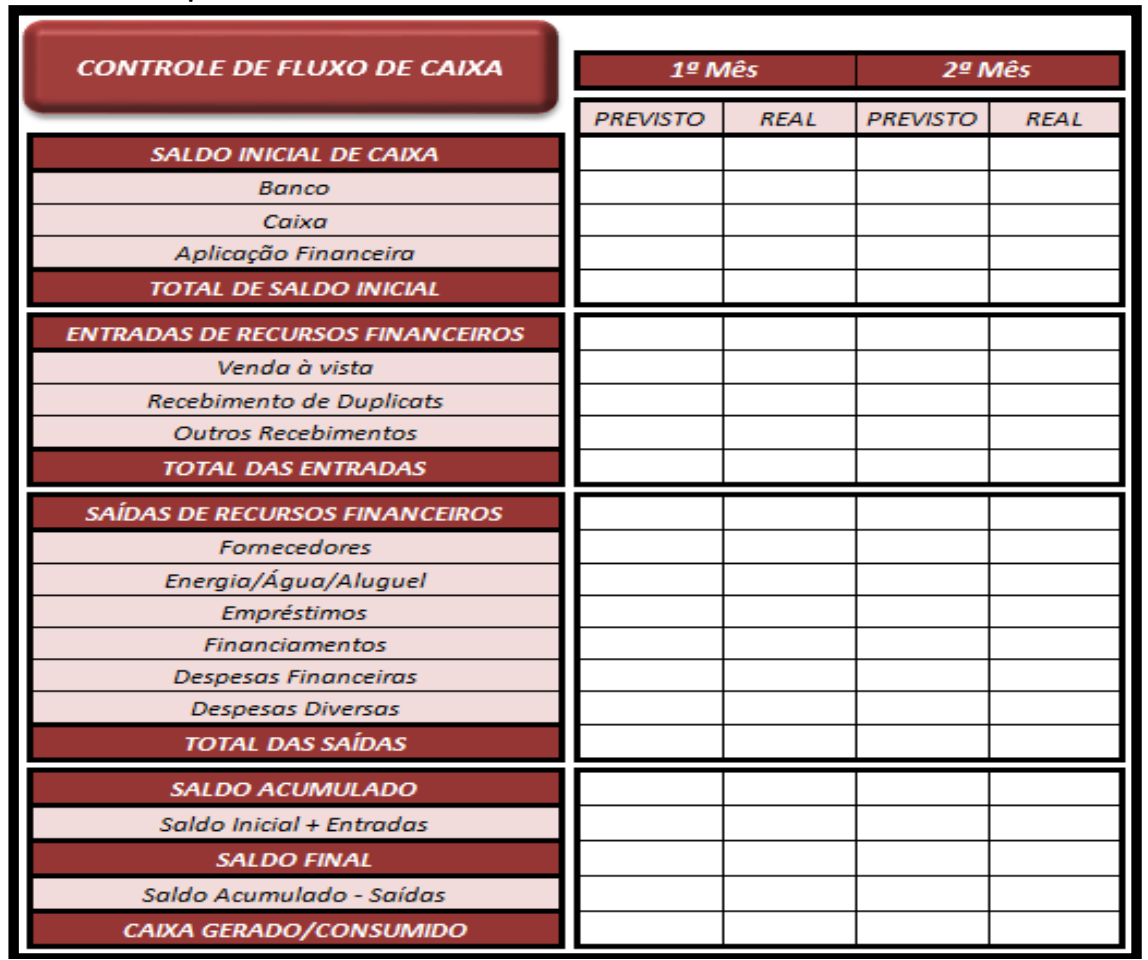

Fonte: Desenvolvido pela autora.

Através desta planilha é possível fazer o controle das entradas e saídas dos recursos financeiros, podendo o gestor verificar no fim de cada período se suas atividades geraram caixa, deixando-o com saldo positivo ou se estas consumiram o caixa, deixando-o com saldo negativo (TÓFOLI, 2012).

\section{BENEFÍCIOS DO FLUXO DE CAIXA E AUXÍLIO NA TOMADA DE DECISÕES}

O controle de fluxo de caixa além de ser uma ferramenta financeira é considerado também como um instrumento gerencial, pois fornece diversos benefícios aos gestores com a finalidade de auxiliar no processo de tomada de decisão (ZDANOWICZ, 2000).

Ching, Marques e Prado (2010), relatam que, através deste controle é possível avaliar a capacidade da empresa de gerar caixa antes mesmo de assumir novos compromissos; de verificar se estará trabalhando com folga ou aperto financeiro; de obter informações relevantes sobre o momento mais favorável para realizar promoções de vendas e a concessão de prazos de pagamento mais adequada no período; de verificar quais as atividades que mais consomem o caixa ou aquelas que contribuem para um aumento dos recursos financeiros.

Já Silva (2016), argumenta que através deste controle é possível planejar as necessidades de captação de recursos e aplica-los de forma eficaz sem comprometer a liquidez, de planejar e controlar os recursos visando o equilíbrio financeiro dos ingressos e desembolsos.

Mediante isto, através das informações fornecidas por este controle é possível o administrador identificar a situação da empresa no período e tomar decisões assertivas caso seja constatado a falta ou sobra de numerários, pois a elaboração do controle de fluxo de caixa traz subsídios que auxiliam os gestores na tomada de decisões (FREZATTI, 2014). 
Com base nisto é possível compreender que a elaboração deste controle não serve apenas para verificar se a empresa irá dispor ou não de saldos em caixa, ele serve também como um auxílio aos gestores na tomada de decisões em um âmbito geral da empresa.

\section{A IMPORTÂNCIA DO FLUXO DE CAIXA PARA AS MICRO E PEQUENAS EMPRESAS}

Mesmo estando desobrigadas a elaboração da DFC (demonstração de fluxo de caixa), é essencial que os administradores realizem um controle de fluxo de caixa, pois normalmente os mesmos se preocupam apenas com a atividade principal da empresa e se esquecem que é preciso de recursos financeiros para dar continuidade em tal finalidade. (SANTOS,2010).

Isto se faz necessário porque as empresas estão inseridas em um ambiente imprevisível e mutável, onde problemas distintos surgem a todo instante, sendo de responsabilidade do administrador se posicionar frente aos mesmos e tomar decisões assertivas de forma que contribua com resultados positivos para a empresa (JOLO, 2012).

Contudo, "uma empresa pode quebrar se não tiver liquidez, isto é, se não tiver dinheiro em caixa para pagar seus compromissos" (CHING; MARQUES; PRADO, 2010, p.175).

Portanto, observa-se que o controle ineficaz dos recursos financeiros ou a falta dele pode fazer a empresa perder competitividade e comprometer sua sobrevivência no mercado.

Á vista disto, para dispor de saldo positivo em caixa é preciso ter uma administração adequada de diversos fatores envolvidos na empresa, como de estoque, de ativos, dos prazos de pagamentos e de recebimentos, pois todos envolvem a utilização de recursos financeiros e caso estes não sejam bem controlados podem levar a utilização inadequada dos mesmos e prejudicar o grau de liquidez da empresa (ZDANOWICZ, 2000).

\section{DISCUSSÃO}

Na maioria das vezes, o administrador das micro e pequenas empresas acabam por ser o próprio proprietário, onde o mesmo não dispõe de conhecimentos básicos para exercer a função que a si mesmo foi designada. Muitos deles acreditam que a gestão de fluxo de caixa deve ser realizada apenas pelas grandes empresas, onde possuem muitos clientes, funcionários, diversos produtos etc., no qual contribuem para uma elevada movimentação no caixa.

No entanto, para que estas empresas se tornem competitivas e garantam sua permanência no mercado é preciso que os gestores considerem este controle como um instrumento gerencial, pois através dele é possível obter informações relevantes que auxiliam no processo de gestão.

Ainda, com o controle de fluxo de caixa planejado o gestor poderá verificar o valor dos recursos financeiros que terá que desembolsar em um determinado período e se o saldo disponível em caixa juntamente com o valor que tem a receber será suficiente para lidar com as obrigações da empresa no momento de seu vencimento.

Desta forma, percebe-se que o controle de fluxo de caixa é fundamental no cotidiano das micros e pequenas empresas, pois com ele os gestores conseguem tomar melhores decisões, melhorando consequentemente os resultados no mercado.

\section{CONCLUSÃO}

De acordo com as ideias trazidas pelos autores e que foram abordadas no contexto deste artigo conclui-se que, a realização do controle do fluxo de caixa é fundamental para a 
sobrevivência das micro e pequenas empresas, pois com a realização de um controle eficaz destes recursos os administradores terão uma visão geral da saúde financeira da organização, podendo antever o surgimento de possíveis problemas e tomar decisões assertivas caso seja constatado a falta ou sobra de numerários, pois estes recursos influenciam em todo o processo organizacional, onde sua maior parte é utilizada para financiar a atividade operacional da empresa, onde caso seja constatado a falta de liquidez a empresa poderá perder a credibilidade dos clientes e dos fornecedores, comprometendo sua sobrevivência no mercado.

Em suma, a gestão bem organizada deve ser realizada desde o início da atividade, pois com isto será possível os administradores estabelecerem metas e objetivos para que sua empresa se torne competitiva de forma que traga bons resultados e cresça no ambiente ao qual está inserida.

Com isso, percebe-se a importância do controle de fluxo de caixa para as micros e pequenas empresas, onde este é considerado uma ferramenta imprescindível para a tomada de decisões, pois é através dos resultados que se obtém do caixa que a empresa irá atuar, destacando a importância do planejamento no controle financeiro, sendo um instrumento gerencial que permite apoiar o processo decisório.

Por fim, havendo uma sincronia no fluxo de caixa, o administrador financeiro terá tranquilidade para definir em qual momento tomará sua decisão, pois com um equilíbrio desejado de ingressos e desembolsos, as decisões serão mais fáceis de serem tomadas, confirmando assim, que o fluxo de caixa é um instrumento que o administrador financeiro tem ao seu alcance para que possa tomar decisões com maior segurança.

\section{REFERÊNCIAS}

ANDRADE, M. M. Introdução à metodologia do trabalho científico. 10 ed. São Paulo: Atlas, 2010.

BRASIL. Congresso Nacional. Lei Complementar № 123, de 14 de dezembro de 2006. Dispões sobre o Estatuto Nacional de Microempresa e da Empresa de Pequeno Porte. Disponível em:<http://www.planalto.gov.br/ccivil_03/leis/LCP/Lcp123.htm>. Acesso em: 05 de mai. 2018.

BRASIL. Congresso Nacional. Lei № 11.638, de 28 de dezembro de 2007. Dispõe sobre a elaboração e divulgação das demonstrações financeiras. Casa Civil, Brasília, DF, 28 de dezembro de 2007. Disponível em:

<http://www.planalto.gov.br/ccivil_03/_ato2007-2010/2007/lei/l11638.htm>. Acesso em: 05 mai. 2018.

CHING, Yuh; MARQUES, Fernando; PRADO, Lucilene. Contabilidade e finanças para não especialistas. 3 ed. São Paulo: Pearson Prentice Hall, 2010.

GIL, A. C. Como elaborar projetos de pesquisa. 4 ed. São Paulo: Atlas, 2002.

GIL, A. C. Como elaborar projetos de pesquisa. 6 ed. São Paulo: Atlas, 2017. Disponível em: $<$ https://integrada.minhabiblioteca.com.br>. Acesso em: 11 mar.2018.

GITMAN, L. J. Princípios de administração financeira.7 ed. São Paulo: Harbra, 2002. 
JOLO. Mariana Veronez. A importância do fluxo de caixa para micro e pequenas empresas na tomada de decisão. Limeira: Unicamp, 2012. Disponível em:

$<$ http://www.bibliotecadigital.unicamp.br/document/?code=000925509\&opt=3>.Acesso em: 13 de mai. 2018.

MARCONI, Marina de Andrade; LAKATOS, Eva Maria. Fundamentos de metodologia científica. 8. ed. São Paulo: Atlas, 2017. Disponível em:

<https://integrada.minhabiblioteca.com.br>. Acesso em: 11 mar. 2018.

SILVA, Edson Cordeiro. Como administrar o fluxo de caixa das empresas: guia de sobrevivência empresarial. 9 ed. São Paulo: Atlas, 2016.

Disponível em: <https://integrada.minhabiblioteca.com.br>. Acesso em: 15 fev. 2018.

TÓFOLI,Irso. Administração financeira empresarial. São José do Rio Preto: Raízes Gráfica e Editora, 2012.

ZDANOWICZ, José Eduardo. Fluxo de Caixa: uma decisão de planejamento e controle financeiro.8. ed. Porto Alegre: Sagra Luzzatto, 2000.

SÁ, C. A. Fluxo de caixa: a visão da tesouraria e da controladoria. 2 ed. São Paulo: Atlas, 2008.

SANTOS, Mariana Szilabyi. O fluxo de caixa aplicado a micro e pequena empresa. 2010. Cacoal: Universidade Federal de Rondônia, 2010. Disponível em:

<http://ri.unir.br/jspui/handle/123456789/186>. Acesso em: 13 de mai.2018.

SEBRAE. Fluxo de caixa: o que é e como implantar. Disponível em:<http://www.sebrae.com.br/sites/PortalSebrae/artigos/fluxo-de-caixa-o-que-e-e-comoimplantar,b29e438af1c92410VgnVCM100000b272010aRCRD>. Acesso em: 10 fev.2018. 